\title{
Janet Lansdale
}

\section{Ancestral and Authorial Voices in Lloyd Newson and DV8's 'Strange Fish'}

\begin{abstract}
Lloyd Newson has worked in Europe for some twenty-three years with DV8 Physical Theatre, creating powerful socio-political pieces which address sexuality and interpersonal relationships. These works are generally created with performers through workshop processes and collaboratively with composers. London's experimental dance and theatre scenes in the 1980s and early 1990s provided a challenging context for Lloyd Newson's early creative endeavours. Here, Janet Lansdale takes one work, Strange Fish, as the locus of her discussion on narrative positions in relation to dominant forms of modern dance and issues of sexuality, homophobia, and politics within physical theatre. She conceptualizes and contextualizes 'voices' as 'authorial' and 'ancestral', and traces their manifestation in readings of the work. Complementary and sometimes competing voices from author, text, reader, and cultural history are articulated through a range of intertextual perspectives. This is the second in a series of articles on this work. ${ }^{1}$ Janet Lansdale is Distinguished Professor in Dance Studies at the University of Surrey, where she was Head of Department, and later Head of the School of Performing Arts. She is the author and editor of four books on dance theory, history, and analysis, the most recent being Dancing Texts: Intertextuality in Interpretation (1999).
\end{abstract}

FIRST, I shall set the scene by sketching very briefly notions relating to narrative that are particularly relevant to Strange Fish. That the creator and performers (Lloyd Newson and collaborators in the company DV8) have a narrative position is perhaps as obvious as the narrative position of the writer of this article. But there are also many other authorial and ancestral dances and sonorities that set the context. These are the dancescapes and soundscapes of the last five centuries in Christianized countries. $^{2}$

There are the narratives that we inherit and absorb often without directly recognizing them, from the body of scholarly writing in dance and physical theatre. They are evident in discourses found in a range of publications and images, from popular journalism to books and journals. The voices that are audible in Strange Fish, a physical theatre work first shown in 1992 and subsequently reworked for video in 1994, are many and varied. Newson's intentions and practices did not coincide happily with many of the existing dance voices - primarily those of abstract modern dance inherited from the US - and I articulate these positions in the first part of the paper.

I make use in particular of the idea of 'ancestral scholarly narratives' of intertextual theory to construct an open-ended argument tracing some of the layers of analysis the work invites. Strange Fish, I argue, invites the reader to produce multiple traces, through the process of setting in play different texts and intertexts. As the reader adopts different positions, so different texts come into focus. Expressed in another way, different 'voices' sing at different moments. In addition to the usefulness of the idea of 'voice' in tracing intertextual threads, the presence of actual and ethereal voices in Strange Fish give this theme particular poignancy. ${ }^{3}$

\section{Pre-Birth Voices of Newson and DV8}

Lloyd Newson's ancestral voices are found in the white, American/Australian/European nexus of 1970s youth culture, in theatre dance, and in popular physical arts. He was born in 1957 in Australia and, while studying psychology at Melbourne University at both 
undergraduate and postgraduate levels, he danced in the Modern Dance Ensemble, an amateur group with release and improvisation interests. Newson came to the UK in 1980, studied briefly at the London School of Contemporary Dance, and joined Extemporary Dance Theatre (EDT) in 1981, producing an early company piece alongside another newly emerging (and equally controversial) choreographer, Michael Clark. ${ }^{4}$ At that time, Emilyn Claid, the Director of EDT, was also commissioning works from other new dance choreographers such as Jackie Lansley, for Speaking Part (1981), and Fergus Early, for Napoli (1982). While Newson might have been impatient to move on, he was already in the only mainstream company in the UK with experimental ambitions, which he acknowledges in interview with Andy Solway. ${ }^{5}$

Newson started his own group, DV8 (deviate) Physical Theatre in 1986, as an independent collective. Among its stated aims was 'to re-invest meaning in dance', clearly implying that modern dance had lost its way and no longer dealt with meaning. Newson's extension of early twentieth-century Expressionist theatre and dance movements is peculiarly European in character, in its focus on the intensity of emotion and on the use of images, words, and movement, separately and together, treating personal, social, and politically intense subject matter. This trend reverberated further than physical theatre to classical ballet and modern dance, where it is embodied in expressionistic treatments of traditional subject matter in these forms, too, although not to the same extent and in very different movement vocabularies. ${ }^{6}$

\section{Dancing Voices of the 1980s}

By the 1980 and 1990 s there existed competing, even mutually exclusive, positions on what was perceived to be 'new' and of value in the contemporary dance scene. I articulate these voices through a comparison of critical views to reveal shifting genre and style boundaries. A useful site is found in annual festivals such as those of Dance Umbrella and Spring Loaded (both London events), which present a large amount of new work.
The group of articles referred to below reflect a ten-year shift across the British dance scene.

Fiona Burnside identifies what she calls 'original' and 'mature' voices in 1980s-1990s British 'contemporary dance' in the work of Richard Alston, Laurie Booth, Rosemary Butcher, and Siobhan Davies. Although recognizing that they do not together make a 'united school of thought based on a common philosophy', she suggests that they none the less share a 'cultural and social heritage which has influenced their absorption and transformation of contemporary dance'. ${ }^{7}$ The qualities and concerns seen in the 'integration of the elements of production' separates these collaborations from the 'jarring juxtapositions of other European work'. In the same breath, she remarks on the conspicuous absence of the kind of 'dramatic narrative... emotional expression, and sexual relations ... shock tactics . . . political ideology' credited to Lloyd Newson.

Burnside sketches the parameters of what might be termed a distinct style, which she likens to 'the exposition, modulation, and recapitulation of a musical score' rather than to 'Aristotelian cathartic theatre'. To support this argument she states that a degree of dedication 'to exploring the formal properties of the dance medium' is obvious where 'intellectual pleasure in ... patterning and a sensual enjoyment of the smooth textures of the movement and the colour range' are most evident. This was hardly a productive starting place for Lloyd Newson.

An 'elegant and reticent aesthetic', but one based on a wider range of themes and moods, characterizes Siobhan Davies's 'bodies in motion', building a 'corporate psyche' rather than individual personalities. A 'wider world is invoked' and a 'larger canvas of human suffering' than (she suggests) Rosemary Butcher ever creates. ${ }^{8}$ Again, this is some distance in stylistic concerns from Lloyd Newson's apparent interests, despite shared reference to an external world. Laurie Booth, Burnside argues, contrasts most obviously with the others and, in deriving his movement in part from martial arts, physical theatre, and contact improvisation, sows the seeds of shared concerns with Newson. 
Booth, however, unlike Newson, elicits response from 'the physical embodiment of the work and not through emotional engagement.

Roughcut, Richard Alston's work discussed by Burnside, is untypical, although sharing with his other works 'technically demanding, physical exploration' which requires 'swift, clean execution and vital energy'. She argues that his work has a greater range of reference to narrative elements, representation, and literary themes than any of the other three choreographers in this group. ${ }^{9}$ This, too, is hardly comfortable artistic company for Lloyd Newson.

Constanti provides something of a counterbalance to Burnside by considering very different types of work in the 1987 Spring Loaded festival at The Place which, she argues, revealed two opposing schools of thought, 'dance which appears to be based (naively?) on 'gratuitous pyrotechnics . . . [and] the retaliatory movement stemming from a vigorous personal/social/political stance'. ${ }^{10}$

She refers to Images and La Bouche's work in terms of 'gratuitous pyrotechnics' and, separately, to the personal stance of Emilyn Claid, Liz Aggiss, and DV8. Reluctance to let 'tragedy become beautiful' is shared by this second group, which she describes as embodying 'hard hitting and compulsive' realism and physical/emotional risk-taking - a more obvious connection for Lloyd Newson.

Unexpected shifts on the borderlines between 'witty nonsense' and 'vicious parody' make Lea Anderson's work for the Cholmondeleys clearly distinctive even while she shares some of these features. Her work is individual in its 'rich, abstract vocabulary, the secret cues and whispers are built into a weird, hermeneutic grid of movement, magically sustained by the infernal animation of Drostan Madden's music - a blend of Velvet Underground, saxophone . . and accordion' ${ }^{11}$

In 1996, nearly ten years later, Jann Parry reflects on the diversity within 'new dance' and particularly in cutting-edge work. She identifies a distinctive concern with constructing narrative and a trend towards spectacle and theatre, a more comfortable environment in which Lloyd Newson plays an important part. ${ }^{12}$ Parry constructs a number of categories and spans a huge field; firstly, ballet-derived work as in the newly re-formed Ballet Rambert under Christopher Bruce; secondly, two individuals, Alston and Davies, as the creators of modernist, developed versions of established contemporary dance techniques.

Emerging more clearly in her account are performers working with a highly physical approach - sometimes called Eurocrash companies. Anne Teresa De Keersmaeker, Wim Vandekeybus, and Claude Brumachon are placed here, but so, too, are circus-trained groups. She links dancers who use martial arts, including Laurie Booth and Russell Maliphant, as a fourth stream; while a fifth category, of English Eccentrics, includes 'an assortment of choreographers whose work is highly idiosyncratic'. Here Parry refers to vastly different individuals from Javier de Frutos to Julyen Hamilton, including Wayne McGregor, Matthew Hawkins, Yolande Snaith, Lea Anderson, Liz Aggiss, and Jonathan Burrows. 'Mature performers', whom she groups separately, include Misha Baryshnikov and Fergus Early.

To this amorphous group of categories, she adds 'club and rave culture' (Bunty Matthias), 'text-based work' (Nigel Charnock, V-Tol, and Second Stride), 'cross-cultural/ intercultural groups' (Vivarta festivals and Shobana Jeyasingh, Peter Badejo), and finally 'new technology dance' (Mark Baldwin). ${ }^{13}$ So the dance world in which Newson worked between 1987 and the end of the 1990 offered some compatible voices and a number of clearly incompatible ones.

\section{A Post-Expressionist Narrative}

Newson's relationship to the ancestral voices of the expressionist tradition is revealed in his deep concern with the legibility of dance. His work relies on his collaborators to 'reveal something of their inner selves', to the degree that the performer may feel 'totally exposed and vulnerable' ${ }^{14} \mathrm{He}$ challenges the modernist idea of the construction of emotional archetypes, aligning himself with postmodernist works in the 1980 s which, more 
typically, draw on autobiography without reserve rather than abstracting from it. ${ }^{15}$

Among the traces of expressionism that may not be obviously relevant is Newson's inheritance of an actual European expressionist dance movement in his native Australia. This tradition owed its origins to Gertrud Bodenwieser's move from Austria in 1938, in the face of difficult political circumstances, to the Southern Hemisphere, where she took Ausdruckstanz. ${ }^{16}$ I do not suggest a direct 'influence' but rather an atmosphere, a culture, of which he was a part and whose voices are still heard. Newson's work is much more than re-articulations of 1930 expressionistic ideas, even though those voices are audible. He has expressed interest in constructing stories that might serve either stage or film and which function through metaphor and allegory. ${ }^{17}$ Far from taking existing stories as the basis of his work, he states that he 'start [s] from an idea and then look[s] for texts with which I can have a dialogue' (my italics). He also refers to starting from an image - a clue that seems to inform Strange Fish in its use of the Cross, in the communion wine, in the presence of candles, and in the lighting choices that evoke religious moods. ${ }^{18}$

Newson reworks ideas within a topical 1990s political agenda using many media, including words. In this sense he flouts the highly valued integrity of expressionist dance - its central concern being for expression through movement alone. Autobiographical fragments published in interviews with Andy Solway, Jann Parry, and Nadine Meisner reveal Newson's view that what dance can do best is deal with 'a very personal investigation' rather than 'social and political themes on a larger theoretical level'..$^{19}$ These personal investigations often concern the individual's place in society and the exclusion of individuals from particular societies.

Two threads can be woven here into the argument. When challenged by a feminist accusation of sexism, he takes up the victim position, saying 'everybody in my pieces were [sic] victims ... we're using the work to explore issues which caused us unhappiness, brought about by our own abilities - as gay men, women - to play underdogs and accept that ${ }^{20}{ }^{20}$ But in recent political argument, and in feminist and post-colonial theory, the notion of difference would be more important than the shared one of victimhood.

The experience of homophobia is different for men and women, and for different age groups; victimhood is different for varied shapes and sizes of people, and for black and white people. Most importantly, the experience of men and women is different, even in contemporary culture. While these voices compete, Newson seems to essentialize experience, a position which is entirely consistent with his expressionist and socialrealist views on art, but one which fails to address difference. Newson even constructs a personal narrative for the dancers based on psychological analysis and a concern with spirituality (a theatre of alienation, perhaps), saying: 'Wendy has lost faith, she's lost friendship, she's lost one of the people she wants as a friend, Nigel, largely through her own actions, and she has isolated herself. In her desperate need for friendship, she has actually alienated herself to the point that she has lost all sense of belief and faith.' ${ }^{21}$

\section{The Voices of Collaborators}

The dancers' individuality and personal commitment are given a voice through improvisational working methods. Parry refers to a three-and-a-half-month period spent improvising and shaping material to create Strange Fish collectively. Newson's collaborators range widely in experience, age, and physique, but each is capable of meeting the challenge of developing movement that is distinctively his/her own, yet appropriate to the theme.22

The individuality of modernism is the vocal thread here. Newson makes particular reference to Diana Payne-Myers's 'fragility and her age', ${ }^{23}$ but social voices also enter in the nature of the roles taken by Diana PayneMyers. She is over sixty years old, and she is sometimes abused, exposed unmercifully perhaps recalling problems the elderly may face in some circumstances. This theatre of cruelty is revealed in a stage scene not used in the video of Strange Fish and in another work, Enter Achilles (1995). 


\section{STRANGE FISH: an outline}

Duration Mins Summary Title

$1 \quad 00.00-03.17$

$2 \quad 03.17-04.42$

$3 \quad 04.04-10.52$

$4 \quad 10.52-15.30$

$5 \quad 15.30-19.08$

$6 \quad 19.08-23.35$

$\begin{array}{lll}7 & 23.35-27.43\end{array}$

$8 \quad 27.43-30.00$

$9 \quad 30.00-39.00$

$10 \quad 39.30-45.03$

$11 \quad 45.30-49.15$

$12 \quad 49.15-54.20$
3.17 Church Scene 1. Religious observance

1.25 Corridor Scene 1. Interrupted conversations

6.10 Bar Scene 1. Intimidation, competition, and co-operation

4.38 Bar Scene 2. Sexual play, two against one (female/male)

3.38 Corridor Scene 2. Dissolving the self, male-female duet

4.27 Bar Scene 3. The party, the isolate, and the group

4.08 Room Scene 1. On being alone and together

2.17 Corridor Scene 3. Intimacy interrupted

9.30 Room Scene 2. Pointless sex and its aftermath

6.00 Corridor Scene 4. Brief tenderness turns to violence

3.45 Room Scene 3. Baptism and absolution

5.05 Church Scene 2. The desecration of the Cross
In interview, Newson emphasizes the importance of the collaborative process. Yet the performers' openness to improvising and to taking responsibility, which he cherishes, has to be balanced against his statement that 'ultimately I do make the decisions, set exercises and edit material'. ${ }^{24}$ In the end, the 'authorial voices' are reduced, or at least focused, through Newson. However, the performers are not the only collaborators, since powerful musical voices intervene.

\section{Ancestral Musical Voices}

The performer/singer Melanie Pappenheim and the composer Jocelyn Pook shared an interest in semi-staged and movement-rich performance long before their collaboration in Strange Fish. Their focus had often been on palindromic verbal and musical structures and on polyrhythmic constructions, of which an earlier composition, A Man, a Plan, a Canal, Panama is an example. Like Pappenheim, Pook is eclectic in her interests and in the range of her work. Both enjoy moving across genres to bring elements of different histories into relationship. ${ }^{25}$

Among the nostalgic forms relevant to the music, as well as to the action, of Strange Fish is the Lament, a historically varied musical and poetic form inspired by rites for the dead or ritual leave-taking (bridal laments). This ceremonial form balances the involuntary cry of grief (the 'planctus') and the deliberate framing of a message (the 'discourse'), representing crisis and order respectively. ${ }^{26}$ In many cultures lamenting is a task entrusted to women, as it is here. The obsessional qualities of the lament are found also in Monteverdi and Purcell, where music becomes a site of excess, a deviation that must be overcome. There is an obvious link to the nostalgic longing for Christ found in Strange Fish and in the compassion for human suffering that Melanie Pappenheim's 'lament' evokes. The understanding of this lament is complicated by the earlier role adopted by this performer as a female Christ-figure. In the lament, she becomes Mary, Mother of God and Intercessor for us all.

Even more obvious is the use of plainsong as a melodic thread through Strange Fish, structuring the musical ideas of Scenes 1, 5, 9, 11 and 12 (see the outline structure, above). The improvisatory vocalizing, typical of plainsong, is inescapably associated with woman, although this contradicts historical traces of the male-only plainsong practice of earlier centuries. Jocelyn Pook and Melanie Pappenheim's music reflects plainsong and lament quite strongly, despite their latetwentieth-century position; and the music is a patchwork of improvised elements. They readily acknowledge their starting points in 
the requiem mass, but worked without recognizable language, and with an awareness of both folk and religious texts, as well as theatrical interests. Their use of prose rhythm provides another direct link to the plainsong period.

\section{Contemporary Traces of Ancient Greece}

Newson is particularly indebted to the wellknown myth of Heracles. It is the siren figure and men's inability to resist the sensuality of women which is traced from these sources. But there is more than one version of the siren stories, and an interesting ambiguity appears in the final scene where Wendy Houstoun, having climbed the cross to reach Melanie Pappenheim, pours the holy wine down her throat and then appears to 'kiss' her - resoundingly, some critics thought. However, there is also evidence of another trace of the myth, which talks of sucking the breath from the dying body. To see Strange Fish as based in several myths and worked through as a 'rite', may help to explain its effectiveness and power. Rather than being dependent on external violence, it operates persuasively through its own effects, generating laughter, seducing the emotions, provoking the reconsideration of ideas, swallowing the audience in sensuality, in movement, and in music, light, and colour. ${ }^{27}$

As Catherine Bell argues, 'The dynamic interaction of texts and rites, reading and chanting, the word fixed and the word preached are practices, not social developments of a fixed nature and significance' ${ }^{28}$ Newson can be configured as a choreographer/theatre maker who 'ritualizes' or 'revocalizes' psychological and mythic events in a late-twentieth-century mode, capturing these events and reworking them using political and consumerist strategies of the present to reinforce the message by mixing ancient and contemporary voices.

Lloyd Newson is not alone in linking contemporary psychological and Greek material. An honourable history exists in modern dance. As in Martha Graham's work, there is often evidence of the individual making sense of her/his own life and her/his choreographic work which results in themes of death, eroticism and the maternal body. ${ }^{29}$ It might be suggested, rather stereotypically, that for Newson, as an avowedly gay male choreographer, the maternal body is of little erotic significance. More to the point, perhaps, is the fear of avenging angels, as in Nigel Charnock's fear of Wendy Houstoun. This draws on an 'almost universal, deeply seated aversion to the female body' which Ramsay Burt attributes to the 'violence and horror of separation' from the mother - a modern psychoanalytic interpretation but one which resonates with Greek obsessions.

An episode embodying this idea appears in the stage version of Strange Fish, which is not repeated in the video version, in which Diana Payne-Myers, the older dancer who appears first of all as a frail, nun-like figure, is tossed around by a group of young men, like a doll or a ball. This sadistic entertainment for immature men on a night out suggests the need to establish their difference.

William Beers's demonstration that public rituals of the current time continue to be rituals of sacrifice seems useful here. ${ }^{30} \mathrm{He}$ argues that, since the 'sacred' is socially constructed, the threat of instability is always present. ${ }^{31}$ Ritual blood sacrifice is a universal occurrence among patrilineal societies. The intrusion of archaic forms of narcissism, it is believed, is the source of anxiety disorders in the modern world. Rage and aggression are common where the individual perceives the activity of others as 'wounds to the self', not as independent of the self.

It is not unreasonable to suggest that Strange Fish can be seen as a ritual of 'blood sacrifice' and, applying Beers's terms, as a male-identified rite that is gender-specific, and an expression of male narcissistic anxiety. Sacrifice is understood as an ancient 'male-bonding' ritual, an act of separation from women by means of which men can both bond with each other and appropriate women's power. This seems a more than adequate characterization of Scene 3 in Strange Fish.

Strange Fish, however, has relatively little bonding overall. Rather, it exposes trauma and critiques very successfully the uncomfortable nature of society's rituals. Charac- 
ters are presented as real individuals, not as representations of some named character or as archetypes. This even extends to Wendy Houstoun using Nigel Charnock's real name in moments of extremis, just as Nigel addresses individuals by their own names in the party scene. These scenes of social interaction perversely seem to cause distress and discomfort for the performers, and do not 'make safe' dangerous feelings in the way myth is supposed to do.

Occasionally, Wendy and Nigel glimpse the possibility of belonging to a duo or group, but this sense does not last: the fleeting moment of comfort serves only to point up its continuing absence. What it does 'make safe' is another layer which says that it is acceptable at the end of the twentieth century to expose our wildest and most bitter moments, as television chat-shows and confessional and 'reality' series appear to demonstrate. Anything less would be trivial perhaps.

\section{Fin de Siècle: Voices of the Millennium}

Strange Fish was extremely popular at the time of its making (1992). It was then televised (1994) and made available on video (BBC/RMArts). ${ }^{32}$ It gave rise to extensive comment, although this was largely confined to short articles which neither exhaust the subject nor uncover its multiple layers and complexities. None of the critics made a connection between the subject matter of this piece and the approach of the end of the millennium. In the meantime, however, 'millennium fever' developed commercial symptoms. Religious aspects were considerably lower key, reflecting the diminution of interest in, and of the dominance of, Christianity in the western world, although events based more loosely on religious themes were prominent in certain artistic contexts.

These manifestations lent support to the idea that, while the number of practising churchgoers in the Anglican Church in the UK had sunk to a new low, the story of the life of Jesus Christ and the institution of the Church remained a powerful and enduring part of western mythology. In the 2001 National Census, the results of which have recently been analyzed, 71 per cent of people in this country still describe themselves as Christian.

An American film, Stigmata (1999, dir. Rupert Wainwright), tells the story of a girl receiving a rosary from her mother in a remote Brazilian village. The wounds of Christ appear on her body. The legitimacy of the claims made for her, and the involvement of the Vatican, testify to the usefulness of this myth as a set of intertexts. There was an exhibition at the National Gallery in London called Seeing Salvation: the Image of Christ (February-May 2000), linked to a BBC TV programme culminating on Easter Sunday. It brought together 79 images of Christ, selected, unlike previous chronological exhibitions, around several themes: 'Sign and Symbol', 'The Dual Nature', 'The True Likeness', 'Passion and Compassion', 'Praying the Passion', 'The Saving Body', and 'The Abiding Presence'.

Harrison Birtwistle's opera was specifically commissioned for 2000. He explored the significance of The Last Supper for the third millennium in a series of dramatic tableaux. He recognizes that these are commodified images, already loaded with history, but perhaps no more or less a commodity than they were in the second, fourth, or fifteenth centuries. Recycling myths and adapting them to fit the changing times is a recurrent pastime of ideology-makers, whether they are religious leaders, politicians, composers, choreographers, or art curators.

\section{Dramatic Narrative Tendencies}

I turn now to voices from within the text. Strange Fish self-consciously asks the reader to address the question of who is telling the story. The narrator is conventionally seen as a reliable, external, prophetic voice. In Strange Fish, however, a number of subject positions can be heard in consequence of the actions of the performers.

Scene 1 seems to engage the reader as if from Wendy Houstoun's point of view as she moves around the foot of the cross and behind the penitent figure kneeling in prayer. The singing voice, on the other hand, encour- 
ages sympathy with the figure suspended on the cross. In Scene 2, the active subjects are Nigel Charnock and Wendy Houstoun, united in private, inwardly focused social interaction. Despite the increasing number of participants in Scene 3, it is Lauren Potter and Wendy Houstoun who seem to be controlling the viewers' perspective by initiating unpleasant attacks on others. Increasingly, one becomes aware of the camera director, particularly in the rapid movement of Scene 4 .

In Scene 5, while sympathy with the lovers is generated, the fact that Wendy is watching, cynically, from the foreground cannot be ignored, since she usurps the viewer's position. From the start of Scene 6, there is an atmosphere of waiting for something to happen as at a party. Nigel enters babbling into this sociable but rather unfocused gathering. From then on, his level of anxiety puts one directly in his position. This is intensified in Scene 7, in close-focused events where Nigel attempts to force his way between other couples. Wendy's slap on his face, when she forces him away, feels like a slap in our own.

In Scene 9, where Wendy and Melanie are present (the latter in the role of the Angel), the narrator's role seems to reside more with Melanie as observer of the futility of human intercourse. Melanie's position also seems to focus Scene 11 as she supports the sick figure, here again in the role of the Angel.

Narrative voices can be perceived not only in the position of narrator but also in the location of scenes. The church scenes are two in number in Strange Fish, strategically placed to set the mood and to create a sense of opening up the work and then closing it. The very framework of a church calls up notions of dignity and humility, reverence and recognition of one's insignificance, belief and prayer (rather than agnosticism and atheism), and judgement.

The most obvious and immediate contrast between the first and last scenes is in the atmosphere and mood. The bar scenes (Scenes 3 and 4 , and then the party scene, Scene 6), emphasize sociability, desirability, mixing with others, meeting and parting, competitiveness, personal success and distress. The original bar scene becomes a party scene illu- minated by coloured lights, and the emphasis shifts from small groups to the larger group. The corridor scenes (Scenes 2, 5, 8, and 10) draw on a different set of texts. Corridors are places for casual meetings, for passing others with barely a glance, or for furtive, secretive, and intimate moments. There is an element of danger in the narrowness of corridors, the possibility of confrontation, and the threat of not being able to escape easily.

Each scene carries different significance within this agenda, as the title and subsequent action reveal. The idea of corridors, perceived as places of potential threat, binds Scenes 8 to 10, whereas Scenes 2 and 5 emphasize more positive and enjoyable aspects of relationships in corridors. While a bar is an open environment from which escape is possible, and a corridor explicitly raises the question of escape, some other smaller rooms carry a more intense message. Scenes 7, 9 and 11 take place in intimate settings, the first in a social space, but one confined by the use of lighting, the second in a 'bedroom', and the third around the sides of a water tank in an enclosed space. There is greater possibility in these environments for deep and genuine communication, whether agonized or joyful.

\section{Individual Voices}

The spaces which the video creates set the scene for individual action. Wendy Houstoun takes the role of the quintessential observer and malicious influence. She is often alone and alienated, but makes constant efforts to disrupt the relationships of others and to manipulate outcomes, as in the bar scenes. Her own attempts at intimacy always seem to be doomed. First conniving with Lauren Potter and then attempting to destroy her is one of Wendy's specialities.

In Scene 4, Molina's self-absorbed sensuality is shattered by Wendy's and Lauren's predatory, circling, teasing game. It is Lauren who succumbs to the male in this disturbing piece, not Wendy, here or ever. Group relationships reveal the underlying individual voices of desperation. Their interactions range in tone from the compulsive emotional dependency of Lauren and Jordi getting together in 
Scene 4 to the compulsive, mindless sex of Wendy and Dale in Scene 9, and the utterly terrifying demonstration of emotional need between Wendy and Nigel, which ends in violence (Scene 10).

Even loving consolation is marred by the bittersweet sadness in Scene 11 of baptism and absolution between Melanie as 'Angel' and Dale, the dying sufferer. Intimidation and competition (Scene 3), with the group lending approval, is compounded by the party (Scene 6), where deeply unkind acts continue. Neither is there mercy or sympathy or pity, as Scene 9's aftermath of sex is judged by the group. The ultimate betrayal is the Judas kiss that Wendy forces on Christ Melanie - since it leads to death.

\section{Conclusion}

It is often argued that the Christian message is described as universal not because everyone believes it but because of its successful assimilation of the pre-Christian religious heritage - the Cross as the tree of life, the ritual use of wine - as well as its continuous use over two thousand years. Ancient stories about fish are also inherited. Tales of Hindu and Chinese goddesses, known as fish goddesses, were the precursors of the penisswallowing Kali, also known as Minaksi (the fish-eyed). Swallowing genitals and giving birth to rivers - and gods - is a significant way not only of expressing the fears of the male (as Freudian commentators suggest), but also of conferring greater power and dignity on the male, mainly by appropriating features particular to women. ${ }^{33}$

Less violent, but still common in many western cultures, is the practice of eating fish on Fridays, recalling the orgiastic fish-eating goddess Salacia. James Davidson argues that the Greeks were passionately fond of fish, which amounted to a dominant obsession in fourth-century discourses. ${ }^{34} \mathrm{~A}$ twist to this story is that the fish involved in this literal or metaphorical seduction may have been a source of occult power, as well as being as 'mouth-watering' as women. Nothing is so simple, however. Interpretations of fish madness may have been ironic, since the appre- ciation of fish - in contrast to the public, sacrificial position of animals - was part of a private and modern discourse of connoisseurship. Comedy at that time included shopping lists, fish menus, and recipes.

The intertextual point is that the texts relevant to Strange Fish have traces of the immediate present, as well as of the supposedly dead past. If it is obvious that 'all texts contain traces of other texts', then a more sophisticated version of this idea draws attention to 'the interactions between texts, producers of texts and their readers' lifeworlds'. ${ }^{35}$

There are several threads of intertextuality and of gender politics operating within the work. Each of these referential strands, and their interactions, are compounded by my own response to the 'texts' that are Strange Fish. They illustrate both the constraints on interpretation and the potential for endless reinterpretation. Paradoxically, intertextuality allows the reader to 'create the text' and, simultaneously, to 'read the text as it wishes to be read'. ${ }^{36}$ Or, expressed in another way, it is 'a tool which cannot be employed by readers wishing to produce stability and order, or wishing to claim authority over the text or other critics', but one which continuously opens up possibilities of reading. ${ }^{37}$

\section{Notes and References}

1. I have published a chapter specifically on the musical landscape as 'Siren Sensualities in Physical Theatre: Lloyd Newson's Strange Fish (1992)', in Linda Austern, ed., Music, Sensation, and Sensuality, Critical and Cultural Musicology, Vol 5 (New York; London: Routledge, 2002), p. 121-36.

2. The use of the term 'ancestral' does not imply here that the relevant texts are necessarily old, although some are.

3. Theoretical underpinnings can be found in the following: Janet Adshead-Lansdale, ed., Dancing Texts: Intertextuality in Interpretation (London: Dance Books, 1999); Graham Allen, Intertextuality (London; New York: Routledge, 200o); Umberto Eco, The Role of the Reader: Explorations in the Semiotics of Texts (Bloomington: Indiana, 1979, 1984); Marco De Marinis, The Semiotics of Performance (Bloomington: Indiana, 1993); and Michael Worton and Judith Still, ed., Intertextuality: Theories and Practices (Manchester: Manchester University Press, 1990). 4. EDT was one of the small companies to emerge, at the Edinburgh Festival in 1975 from the burst of activity at The Place which followed the first performances of London Contemporary Dance Theatre in 1967. EDT became a well-respected middle-scale 
company. Emilyn Claid's appointment as Artistic Director in 1981 heralded a change of direction towards experimental dance and to politically charged work. Newson produced Breaking Images in 1982, Beauty, Art, and the Kitchen Sink in 1984, and three workshop pieces in 1983 and 1984 for EDT.

5. Andy Solway, 'Lloyd Newson interview' New Dance, No. 34 (Autumn 1985), p. 10-11. A more extended account of the works produced by the company, their subject matter, and treatment, can be found on the company website www.dv8.co.uk.

6. As in the work of de Valois for the Royal Ballet and Cohan for London Contemporary Dance Theatre.

7. Fiona Burnside, 'Home Thoughts from Abroad', Dance Theatre Iournal, IX, No. 3 (Spring 1992), p. 30-3, 42.

8. More recent analyses of Butcher's and Davies's work can be found in Libby Worth and Sophia Preston's articles respectively, both in Janet Adshead-Lansdale, ed., Dancing Texts: Intertextuality in Interpretation (London: Dance Books, 1999).

9. The criteria on which Burnside bases her stylistic judgements emerge and, of course, the weakness of attempting generalizations in a modernist, individualistic dance form become clear. However, it is a worthwhile exercise in that similarities and differences do emerge, while even the most individualistic of dancemakers can be seen to emerge from specific local and cultural contexts.

10. Sophie Constanti, 'Easing the Load', Dance Theatre Journal, V, No. 2 (Summer 1998), p. 26-9.

11. More recent analyses of Anderson's work can be found in Dodds, in Adshead-Lansdale., ed., 1999.

12. 'Dance on the Edge', Dance Now, V. No. 4 (Winter 1996-7), p. 67-75.

13. It is easy to criticize this attempt to classify work, and these categories would not stand up to detailed analytic scrutiny; but Parry's reflections embody the view of the time as well as a critical attempt to sort out the many emerging trends.

14. Lloyd Newson, 'Lloyd Newson about Strange Fish', Dance and Dancers, July 1992, p. 10-13.

15. In this he has been likened to Pina Bausch, Jan Fabre, and other European choreographers of recent years.

16. Patricia Grayburn, ed., Gertrud Bodenwieser 18901959 (Guildford: University of Surrey, 1990).

17. Jann Parry, 'Outside Dance', Dance Theatre Journal, VIII, No. 3 (Autumn 1990), p. 43

18. On inspection, references to him starting with a scenario or score or narrative in Strange Fish reveal very cursory document with no more than brief outlines of scenes.

19. See, for example, Nadine Meisner, 'Strange Fish', Dance and Dancers, July 1992, p. 10-13; 'Lloyd Newson on . . Dance', Dance Now, II, No. 2 (Summer 1993), p. 11-13; Jann Parry, 'Strange Fish', Dance Now, I, No. 3 (Autumn 1992), p. 22-7; Andy Solway, 'Lloyd Newson Interview' New Dance, No. 34 (Autumn 1985), p. 10-11.

20. Dennis O'Toole, 'Raw Fish', The List, Glasgow, 5-18 June 1992.
21. Nadine Meisner, 'Strange Fish', Dance and Dancers, July 1992, p. 10-13.

22. Jann Parry, 'Strange Fish', Dance Now, I, No. 3 (Autumn 1992), p. 22-7.

23. Nadine Meisner, 'Strange Fish', Dance and Dancers, July 1992, p. 10-13.

24. 'Lloyd Newson on ... Dance', Dance Now, II, No. 2 (Summer 1993), p. 11-13.

25. Pook is a member of ' 3 or 4 Composers' and 'Elektra Strings'. This latter group of six women work on music performance/theatre projects as well as pop bands. She has worked with Eurythmics, the Communards, the Manic Street Preachers, Meat Loaf, the Stranglers, and Style Council. Her commissions for DV8 include My Body, Your Body (1988); MSM (1994); and for 'O Vertigo Dance Company', Deluge (1994). Pappenheim's musical experiences, first as a choral scholar at King's, London, have taken her across Europe and have covered Lieder, early music, and Kurt Weill.

26. The lament still flourishes in folk forms in Mediterranean areas in Europe, e.g., in Hungary.

27. Rather than affirming 'clear and dogmatic values ... ritual actually constructs an argument, a set of tensions' (Catherine Bell, Ritual Theory, Ritual Practice Oxford: Oxford University Press, 1992, p. 145); and it does this on its own terms, in its own language, not pretending to be something else. It is this perspective that resonates with Strange Fish.

28. Catherine Bell, Ritual Theory, Ritual Practice (Oxford: Oxford University Press, 1992).

29. Ramsay Burt, 'Dance, Gender, and Psychoanalysis', Dance Research Journal, XXX, No. 21 (Spring 1998), p. 30-3, 42.

30. On the symbolic in culture, William Beers uses the work of Mary Douglas and Victor Turner, and in particular the articulation of 'structural conflicts and contradictions, which symbols initiate, conceal, and transform', while criticizing the absence of a psychodynamic position in work of this kind. William Beers, Women and Sacrifice: Male Narcissism and the Psychology of Religion (Detroit: Wayne State University Press, 1992), p. 40.

31. As Mary Douglas argues, in Purity and Danger (London: Routledge, 1966), all social systems can be seen to be 'at war with themselves'.

32. Lloyd Newson and David Hinton, Strange Fish (BBC/RMArts video, 1994).

33. Jan Bremmer, Interpretation of Greek Mythology (Australia: Croom Helm, 1987).

34. James Davidson, Courtesans and Fishcakes: the Consuming Passions of Classical Athens (London: Fontana, 1998).

35. Ulrike Meinhof and Jonathan Smith, ed., Intertextuality and the Media (Manchester: Manchester University Press, 2000).

36. Umberto Eco, The Role of the Reader: Explorations in the Semiotics of Texts (Bloomington: Indiana University Press, 1979, 1984).

37. Graham Allen, Intertextuality (London; New York: Routledge, 2000) 